\title{
Toxicity Biosensor for Sodium Dodecyl Sulfate Using Immobilized Green Fluorescent Protein Expressing Escherichia coli
}

\author{
Lia Ooi, ${ }^{1}$ Lee Yook Heng, ${ }^{1,2}$ and Asmat Ahmad ${ }^{2}$ \\ ${ }^{1}$ Southeast Asia Disaster Prevention Research Initiative (SEADPRI-UKM), LESTARI, National University of Malaysia, 43600 Bangi, \\ Selangor, Malaysia \\ ${ }^{2}$ Faculty of Science and Technology, National University of Malaysia, 43600 Bangi, Selangor, Malaysia
}

Correspondence should be addressed to Lee Yook Heng; leeyookheng@yahoo.co.uk

Received 17 September 2014; Revised 17 December 2014; Accepted 18 December 2014

Academic Editor: Qingjun Liu

Copyright (C) 2015 Lia Ooi et al. This is an open access article distributed under the Creative Commons Attribution License, which permits unrestricted use, distribution, and reproduction in any medium, provided the original work is properly cited.

\begin{abstract}
Green fluorescent protein (GFP) is suitable as a toxicity sensor due to its ability to work alone without cofactors or substrates. Its reaction with toxicants can be determined with fluorometric approaches. GFP mutant gene (C48S/S147C/Q204C/S65T/Q80R) is used because it has higher sensitivity compared to others GFP variants. A novel sodium dodecyl sulfate (SDS) toxicity detection biosensor was built by immobilizing GFP expressing Escherichia coli in $k$-Carrageenan matrix. Cytotoxicity effect took place in the toxicity biosensor which leads to the decrease in the fluorescence intensity. The fabricated E. coli GFP toxicity biosensor has a wide dynamic range of $4-100 \mathrm{ppm}$, with LOD of $1.7 \mathrm{ppm}$. Besides, it possesses short response time $(<1 \mathrm{~min})$, high reproducibility $(0.76 \%$ $\mathrm{RSD}$ ) and repeatability $\left(0.72 \% \mathrm{RSD}, R^{2}>0.98\right)$, and long-term stability (46 days). E. coli GFP toxicity biosensor has been applied to detect toxicity induced by SDS in tap water, river water, and drinking water. High recovery levels of SDS indicated the applicability of $E$. coli GFP toxicity biosensor in real water samples toxicity evaluation.
\end{abstract}

\section{Introduction}

Green fluorescent protein (GFP) was first detected in Aequorea victoria, a type of jellyfish, in 1961 [1], but the cloning of the GFP gene only took place 29 years later [2]. GFP possesses several characteristics which make it exceptional; among the characteristics, it does not require cofactors or substrates, is stably expressed as a fusion protein, is relatively nontoxic, and can be readily detected by fluorescence microscopy and other fluorometric techniques [3]. The wild type chromophore is excited with blue light or UV at $396 \mathrm{~nm}$ or $475 \mathrm{~nm}$ and emits green fluorescence at $508 \mathrm{~nm}$ [4]. There are many GFP variants that have been created with shifted absorbance and emission spectra, improved folding, and expression properties. The creation of blue, cyan, yellow, and red GFP variants coupled with new fluorescence imaging approaches has created more potential of GFP in proteins and biosensor studies [3]. Escherichia coli
GFP is one of the examples where GFP mutant gene (C48S/ S147C/Q204C/S65T/Q80R) was introduced and expressed in E. coli bacteria.

Water resources are reported to be polluted by pollutants (nanoparticles, pesticides, pharmaceutical, industrial waste, by-products from water treatment plants, etc.) very frequently in these few decades. Surfactants are one of the pollution agents [5] and the presence of surfactants as pollutants is also reported in filtered and treated tap water and drinking water. Surfactants play an important role in decreasing the surface tension of water and allow removal and breakdown of stain or grease particles to take place. Sodium dodecyl sulfate (SDS), also known as sodium lauryl sulfate (SLS), a primary alkyl sulphate with chemical formula $\mathrm{CH}_{3}\left(\mathrm{CH}_{2}\right)_{11} \mathrm{OSO}_{3} \mathrm{Na}$, is a member of alcohol sulfate family. SDS is one of the anionic surfactants and it takes up a large part in human life, from appearing in the household [6]. SDS will get into the water resources through outfalls of waste 
water or through direct application such as agrochemical sprays $[7,8]$, dispersants, and pesticides [6]. SDS is widely used in biochemical research in cell lysis, in DNA extraction via SDS-PAGE, and as viral biocide [9].

SDS has been reported toxic to aquatic organisms. In fish species, it enhances organ morphologies such as kidney and spleen, alteration of metabolism rate and swimming ability, and changes in growth and death rates [10-12]. SDS shows acute effect to fertilization of ova and sperm, decreasing probability of fertilization in fish [12]. SDS is also reported to be toxic to mammals such as rodents and human [13]. Exposure of SDS to mammals results in physical and biochemical effects: skin irritation, hyperplasia, alteration of serum lipid composition, damage of cells, and decrease in cell proliferation [14-16]. Detection of SDS via chemical analytical methods through capillary electrophoresis, gas chromatography, HPLC, and UV-V has drawbacks such as difficulty to determine LOD with large sample volume, low detection and volatilization rates, production of toxic waste during operational analysis, high cost, and causing damage to sample during detection process [17-19]. The use of dye to bind with SDS in water has been suggested for the quantification of SDS concentration, but there is challenge to produce specific binding of the dye with SDS $[20,21]$. Not many SDS-detection biosensors have been reported. While several bacterial biosensors were produced to assist SDS detection, most of them were reported to have long response time (minutes to hours), short dynamic linear range, low reproducibility, and short term of stability [22-24]. In this study, we report a sensitive SDS-detection toxicity biosensor fabricated with immobilization of E. coli GFP which was found to have improved properties.

\section{Materials and Methods}

2.1. Materials. Ampicillin, 2-[4-(2-hydroxyethyl)piperazin1-yl]ethanesulfonic acid (HEPES), sodium dodecyl sulfate (SDS), and sodium chloride $(\mathrm{NaCl})$ were purchased from Sigma-Aldrich. Nutrient agar and glycerol were purchased from MERCK and HMBC Chemicals, respectively. Yeast extract and tryptone were purchased from Becton Dickinson and Company. All materials used in this study are of the highest purity available. Solutions were prepared in deionized water (Barnstead RO Thermo Scientific).

2.2. Cultivation of Recombinant Bacteria E. coli GFP. E. coli GFP colonies were produced by spreading the bacterial stock on nutrient agar and incubated under $37^{\circ} \mathrm{C}$ for 18 hours. Single colony of bacteria has been inoculated in $4 \mathrm{~mL}$ LuriaBertani medium (LB: $10 \mathrm{~g} / \mathrm{L}$ tryptone, $5 \mathrm{~g} / \mathrm{L}$ yeast extract, $10 \mathrm{~g} / \mathrm{L}$ of $\mathrm{NaCl}, \mathrm{pH} 7.0$ ) with $100 \mu \mathrm{g} / \mathrm{mL}$ ampicillin added. Preculturing of $E$. coli GFP bacteria has been carried out in a rotary thermoshaker and has been set at $250 \mathrm{rpm}$, $37^{\circ} \mathrm{C}$, for 18 hours (until $\mathrm{OD}_{600}$ reached $1.3 \mathrm{ABS}$ ). $500 \mu \mathrm{L}$ of yielded recombinant bacteria from the preculture was further cultivated in $50 \mathrm{~mL} \mathrm{LB}$ medium for 4 hours (optical density $600 \mathrm{~nm}$ reached 0.8-0.84 ABS) [25]. Bacteria E. coli GFP that has been cultured was centrifuged under $3000 \mathrm{rpm}$ at $25^{\circ} \mathrm{C}$ for $10 \mathrm{~min}$; the supernatant was discharged. It was then

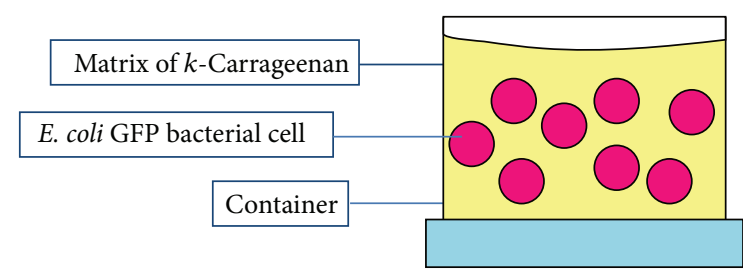

FIgURE 1: The design of E. coli GFP toxicity biosensor.

washed twice with $5 \mathrm{mM}$ 2-[4-(2-hydroxyethyl)piperazin-1yl] ethanesulfonic acid (HEPES) buffer with $171 \mathrm{mM} \mathrm{NaCl}, \mathrm{pH}$ 7.0, under the same condition [26]. Bacterial cells in pellet form were suspended in $10 \mathrm{~mL}$ HEPES buffer and kept in $4^{\circ} \mathrm{C}$. The bacteria culture is ready to be used in the following steps.

E. coli GFP bacteria strain was selected because it is more sensitive and fast in giving a response compared with the rest of the GFP mutants. Wild type GFP was not considered because of its weak fluorescence signal. Single colonies were obtained from the nutrient agar after $20 \mu \mathrm{L}$ of E. coli GFP from glycerol stock was spread equally and allowed to grow on the agar. Ampicillin was added into the nutrient agar as well as the LB medium, to ensure plasmid maintenance of the bacteria $E$. coli GFP. The bacteria cultures were washed twice with HEPES buffer to eliminate excessive LB medium and also organic wastes that were produced during the growing and duplication process of the bacteria.

2.3. Fabrication of E. coli GFP Biosensor. Toxicity biosensor is fabricated by immobilizing E. coli GFP bacterial cells in $k$-Carrageenan matrix. Immobilization process was carried out on a hot plate with temperature set to $40-45^{\circ} \mathrm{C}$. A round container ( $d=8 \mathrm{~mm}$ ) was used as a mould for the immobilization to take place. Figure 1 illustrates the design of E. coli GFP toxicity biosensor. Optimized amount of E. coli GFP cells (warmed in $35-40^{\circ} \mathrm{C}$ water bath) was mixed with optimized concentration of $k$-Carrageenan agar (kept in liquid form under $40-45^{\circ} \mathrm{C}$ heating). Temperature for biosensor preparation was set in between 35 and $45^{\circ} \mathrm{C}$, which is a suitable temperature range for active survival of bacteria. Mixture was stirred well to make sure there was no formation of gas bubbles in the matrix and to produce a smooth surface. Homogenous mixture was kept in $4^{\circ} \mathrm{C}$ overnight to allow thorough solidification to take place.

2.3.1. Immobilization Matrix Optimization. Six concentrations of $k$-Carrageenan matrix were prepared: $1.0 \%, 1.2 \%$, $1.4 \%, 1.6 \%, 1.8 \%$, and $2.0 \%$. All of them were prepared by mixing the specific amount of $k$-Carrageenan powder with deionized water in which the temperature was fixed at $75^{\circ} \mathrm{C}$, which is the temperature needed for $k$-Carrageenan powder to dissolve homogeneously in the solvent; higher temperature will denature the $k$-Carrageenan structure. Continuous stirring was set to allow homogenous mixture to form. A constant amount of E. coli GFP was then immobilized in $100 \mu \mathrm{L}$ of $k$ Carrageenan matrix, for all six concentration measures. Each concentration was prepared in 3 repetition sets. The mixtures were kept in $4^{\circ} \mathrm{C}$ overnight. Toxicity biosensors with different 
concentrations of $k$-Carrageenan matrix were then interfaced with fluorescence spectrometer (discussed in detail in Section 2.4). The parameter of biosensor which gives the highest fluorescence reading will be chosen as the optimum one, and that parameter will be set as constant in the following optimization steps.

2.3.2. E. coli GFP Cell Density Optimization. Five different densities of E. coli GFP bacterial cells were prepared: 5.84, $11.68,14.6,17.52,23.36$, and $29.2 \mu \mathrm{g} / \mathrm{mL}$. All of them were obtained by dilution and concentration of bacterial culture in LB medium (obtained via process mentioned in Section 2.1). The specific amount of $E$. coli GFP was then immobilized in $100 \mu \mathrm{L}$ of $k$-Carrageenan matrix, with the optimized concentration measures in Section 2.3.1. Each amount of $E$. coli GFP was immobilized in four similar repetition sets. The mixtures were kept in $4^{\circ} \mathrm{C}$ freezer overnight. The as-prepared biosensors were then interfaced with fluorescence spectrometer (details discussed in Section 2.3); the optimized cell density was determined from set of biosensors which gave the highest fluorescence reading.

2.4. Fluorescence Response Measurement. Toxicity biosensors which consist of E. coli GFP cells immobilized in the $k$ Carrageenan matrix were tested with fluorescence optical fibre probe which acted as a transducer. Fluorescence signals of each toxicity biosensor have been measured with an optical fibre probe which was placed $10 \mathrm{~mm}$ above the biosensor, where the probe was connected to a Perkin Elmer fluorescence spectrometer. The excitation wavelength was fixed at $395 \mathrm{~nm}$ and emission wavelength was scanned from 400 to $500 \mathrm{~nm}$. Bandwidths of excitation and emission were both set at $5 \mathrm{~nm}$. The reading of fluorescence signals has been measured and read at $436 \pm 2 \mathrm{~nm}$. Optical fibre probe was set $10 \mathrm{~mm}$ above the biosensor samples each time, to ensure that no additional manipulated variable was added into the experiment. Excitation and emission bandwidths were fixed due to the same reason. $5 \mathrm{~nm}$ wide was the best gap to keep away the noises created during the experiment and at the same time was sufficient enough to capture returning fluorescence signals.

\subsection{Performance Evaluation of Toxicity Biosensor E. coli GFP}

2.5.1. Stability of E. coli GFP Toxicity Biosensor. The operational definition of stability of $E$. coli GFP toxicity biosensor is the time frame when the biosensor gives out persistent fluorescence signal not less than $75 \%$ as compared to initial measurement. Fluorescence signal is the referral unit for biosensor stability. 10 sets of biosensor with optimized immobilization parameters have been prepared, sealed with parafilm, and stored in $4^{\circ} \mathrm{C}$. A drop of $10 \mu \mathrm{L}$ of $\mathrm{pH} 7.0$ HEPES buffer was dropped onto the biosensor each time after measurement to maintain the moisture of the matrix before it was resealed with parafilm and returned into $4^{\circ} \mathrm{C}$ freezer. Fluorescence emissions of the toxicity biosensor were measured daily or within interval until a sharp drop in the fluorescence signal of toxicity biosensor observed.
2.5.2. Repeatability and Reproducibility Studies. The repeatability value of the E. coli GFP toxicity biosensor was determined by calculating the percentage of relative standard deviation (\%RSD) of the fluorescence intensity of ten sets of toxicity biosensor which were all prepared with optimized parameters and exactly the same technique, while the reproducibility value of the E. coli GFP toxicity biosensor was determined by calculating the \%RSD of the response of the toxicity biosensors, which were prepared from three different batches, with five replicates each, towards a series of SDS concentrations $(20,40,60$, and $100 \mathrm{ppm})$. The exposure time was $5 \mathrm{~min}$.

\subsubsection{Determination of IC50 of SDS towards E. coli GFP} Toxicity Biosensor. Half maximal inhibitory concentration (IC50) is a measure to determine the toxicity level of a chemical towards living organisms. The IC50 value of SDS towards the E. coli GFP cells immobilized onto the toxicity biosensor is determined by exposing the biosensor to 12 concentration parameters of SDS in the range of 1-100 ppm. $50 \mu \mathrm{L}$ of SDS from each concentration was exposed to the toxicity biosensor. Approximately three replicates were prepared for each parameter. Toxicity biosensors were interfaced with fluorescence optical fibre probe, and readings were recorded before the exposure to surfactant SDS $\left(F_{o}\right)$ and 5 min after exposure $\left(F_{t}\right)$. Percentage of relative fluorescence unit (\%RFU) for each SDS concentration was determined using the formula as follows:

$$
\% \mathrm{RFU}=\frac{F_{o}-F_{t}}{F_{o}} \times 100 \% .
$$

The value of \%RFU indicates the inhibitory level of SDS towards E. coli GFP toxicity biosensor. A graph of inhibitory percentage versus SDS concentration is plotted. The IC50 value is determined from the graph.

2.5.4. Evaluation of E. coli GFP Toxicity Biosensor towards $S D S$ Detection. The calibration curve of $E$. coli GFP toxicity biosensor was determined by exposing the biosensor towards $50 \mu \mathrm{L}$ SDS with 29 concentrations ranging from 0.1 to $1000 \mathrm{ppm}$. The changes in fluorescence before and $5 \mathrm{~min}$ after exposure of the toxicity biosensor were determined. Five replicates were prepared for each concentration. \%RFU for each measure was calculated. The linear range and the lowest detection limit of the toxicity biosensor were established from the calibration curve.

2.5.5. Real Sample Exposure and Recovery Studies. Water samples were collected from three different sources from areas around the National University of Malaysia (UKM): (a) tap water collected from the Chemical Sensor and Biosensor Lab, UKM; (b) river water collected from Langat River, Cheras; and (c) filtered drinking water collected from Kajang town. Water sample (b) was filtered with a Whatman qualitative paper number 6 and number 2 to remove suspended particles that will distort the readings of fluorescence intensity. SDS solutions with five concentration measures $(10,20$, 50,80 , and $100 \mathrm{ppm}$ ) were prepared in the real water samples. E. coli GFP toxicity biosensors were exposed to SDS in different water backgrounds. Induction response with the addition 


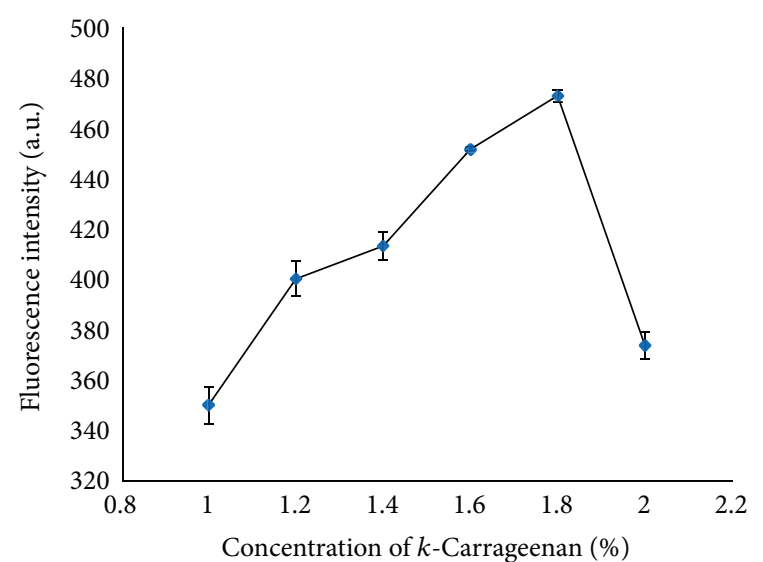

FIgURE 2: The fluorescence emission spectra of the bacteria $E$. coli GFP cells immobilized in $k$-Carrageenan matrix $(n=4)$.

of surfactant SDS has been carried out. The experiment was done with five-sample repetition. The ability of $E$. coli GFP toxicity biosensor to work under real water background has been studied.

\section{Results and Discussion}

3.1. The Optimization of E. coli GFP Toxicity Biosensor. In the fabrication of $E$. coli GFP toxicity biosensor, two major parameters have been studied: the concentration of the immobilization matrix and the E. coli GFP cell density to be immobilized. Matrix $k$-Carrageenan has been selected for the ease of its preparation procedure, its gelling temperature falls in the range that is tolerable by E. coli GFP cells, it is not toxic to the bacterial cells, and its clear nature allows optical measurement to be done. $k$-Carrageenan is hydrophilic and will be surrounded by water molecules which brought to the process of gelation [28]. The presence of $\mathrm{Na}^{+}$cations from the cell suspension buffer enhances the formation of double helix domain of $k$-Carrageenan as proposed by the Domain Model which gives a more rigid structure to the toxicity biosensor [29-31].

Figure 2 shows the effect of the concentration of immobilization matrix to the fluorescence intensity of the toxicity biosensor. It can be understood that the gel viscosity and rigidity increase with the gel concentration, but the optimized gel concentration appeared to be $1.8 \%$ instead of $2.0 \%$. Continuous increment in the fluorescence readings was observed for E. coli GFP immobilized in $1.0-1.8 \% k$-Carrageenan matrix. $1.0 \%$ of $k$-Carrageenan appeared to be too watery and was unable to fix the bacteria stationarily, causing bacteria cells to sediment overnight due to gravitation force. The stacking of bacteria cells at the bottom of the biosensor mould blocked the emission of fluorescence from being detected accordingly by the fluorescence spectrometer, giving out low readings. Same explanations applied to biosensors fabricated in $1.2-1.6 \%$ of $k$-Carrageenan, which showed improving immobilization ability while, for $k$-Carrageenan $2.0 \%$, it was too thick to be manipulated in the immobilization approach. The gelation took place within a few seconds when gel-cell

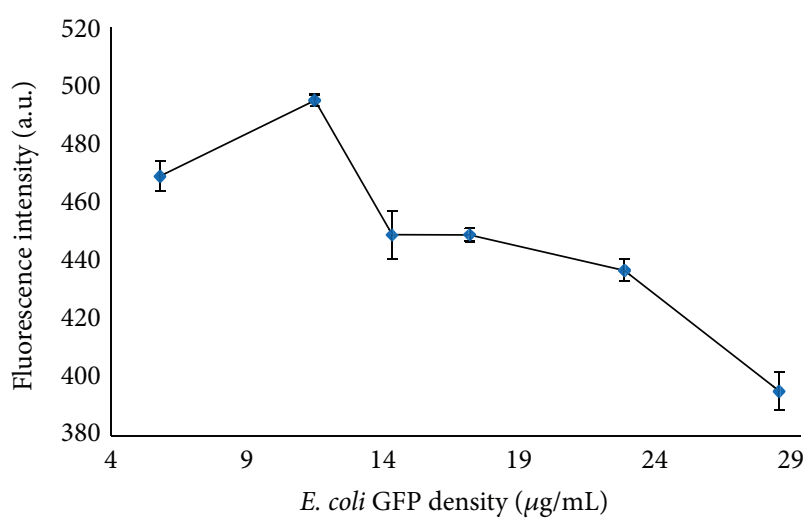

FIGURE 3: The fluorescence emission spectra of the bacteria E. coli GFP cells with varying cell densities $(5.84,11.68,14.6,17.52,23.36$, and $29.2 \mu \mathrm{g} / \mathrm{mL})$ immobilized in $1.8 \% k$-Carrageenan matrix $(n=4)$.

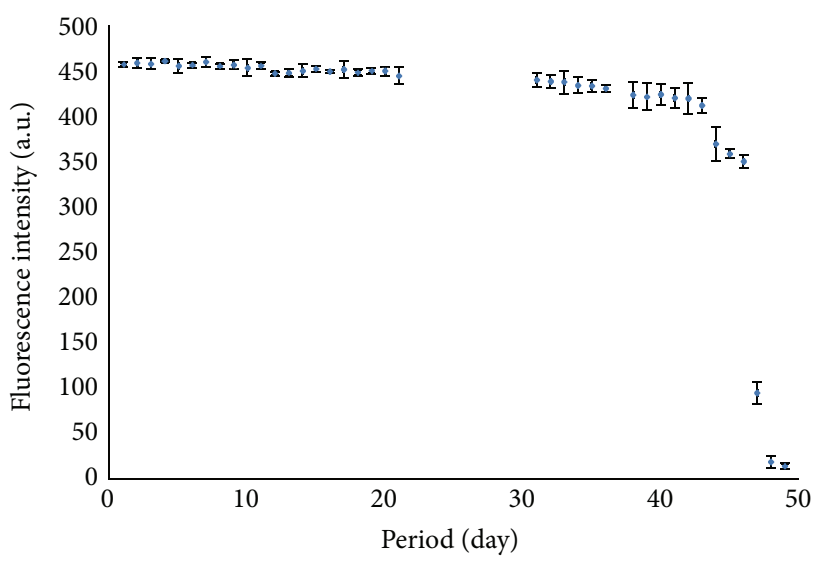

FIGURE 4: Long-term stability of E. coli GFP toxicity biosensor.

mixture was prepared. Even distribution of the bacterial cells could not be achieved before the gel solidified, leading to stacking of bacteria. $1.8 \%$ is the optimum concentration of $k$-Carrageenan, which fixes the bacteria cells firmly while allowing thorough stirring of mixture.

Figure 3 shows the effects of immobilized E. coli GFP cell density on the fluorescence emission of the toxicity biosensor. Similar stacking theory applied in the optimization of cell density of E. coli GFP graph, where the decrease in the fluorescence readings, after $11.68 \mu \mathrm{g} / \mathrm{mL}$, was due to overloading of bacteria. Increasing bacteria quantity beyond the immobilization limit of the $k$-Carrageenan matrix will lead to overcrowded bacteria cells in a constant amount of matrix. This situation ends with stacking of bacteria cells. Fluorescence light emitted by the bacterial cells at the bottom of the container will not be able to be detected by the fluorescence spectrometer. This situation brought the reverse results, where the more bacteria were being immobilized, the less fluorescence readings were being recorded.

3.2. E. coli GFP Toxicity Biosensor Performance. The E. coli GFP toxicity biosensor is stable for a period of 46 days (Figure 4). The biosensor signal remained in the range of 
TABLE 1: Response of $E$. coli GFP toxicity biosensors prepared from three different culture batches towards SDS (20-100 ppm) exposure, $n=5$.

\begin{tabular}{lcc}
\hline Set biosensor & Sensitivity $(\% / \mathrm{ppm})$ & $R^{2}$ value \\
\hline 1 & $61.39 \pm 0.32$ & 0.9877 \\
2 & $62.19 \pm 0.76$ & 0.9875 \\
3 & $62.12 \pm 0.62$ & 0.9833 \\
\hline
\end{tabular}

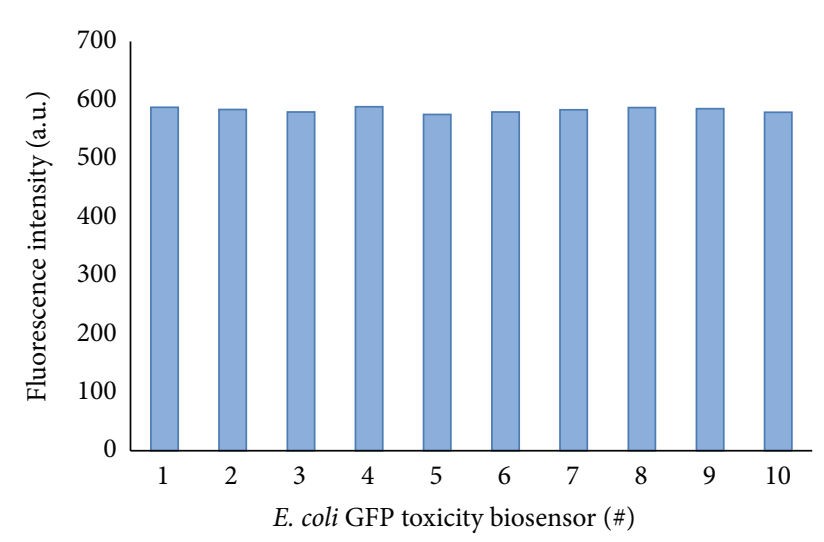

FIGURE 5: Stability of fluorescence signal of E. coli GFP toxicity biosensors which were prepared under constant conditions.

$442.04 \pm 13.94$ for the first 43 days. The fluorescence signal dropped $79.36 \%$ from Day 1 and decreased to $2.80 \%$ starting Day 47. The decrement of fluorescence signal is caused by increased cell death due to depletion of nutrient and toxicity of respiratory residue.

A series of ten $E$. coli GFP toxicity biosensors have been fabricated and the fluorescence intensity of each biosensor was detected and compared (Figure 5). Fluorescence signals obtained fall in the range of $582.50 \pm 4.45$, giving a value of $0.76 \%$ for $\%$ RSD.

Repetition of SDS exposure (20-100 ppm, $n=5)$ for E. coli GFP toxicity biosensor prepared from three different batches of bacteria culture (labeled sets 1-3) shows similar level of sensitivity (Table 1). All three sets of E. coli GFP toxicity biosensor gave an average sensitivity of $61.90 \pm$ $0.44 \% / \mathrm{ppm}$, with $R^{2}$ value $>0.98$. The toxicity biosensor response towards SDS gave \%RSD of $0.72 \%$.

3.3. Response of E. coli GFP Toxicity Biosensor towards SDS Detection. The fluorescence intensity of the E. coli GFP toxicity biosensor decreased when it was exposed to SDS. Different concentrations of SDS induced different levels of decrement in the biosensor response. SDS causes cell toxicity to E. coli GFP which led to decline of fluorescence signal. Figure 6 shows the overall responses of the E. coli GFP toxicity biosensor to $10 \mathrm{ppm}$ SDS exposure. Before exposure to SDS solution, the biosensor gave out a total fluorescence intensity of 976.56. We can understand that, at this stage, the "always on" E. coli GFP biosensor expressed the GFP proteins to its fullest, while after a few seconds when 10 ppm SDS solution was added, the fluorescence intensity dropped to 882.58 . The SDS toxicity started to take place and that gave effect on

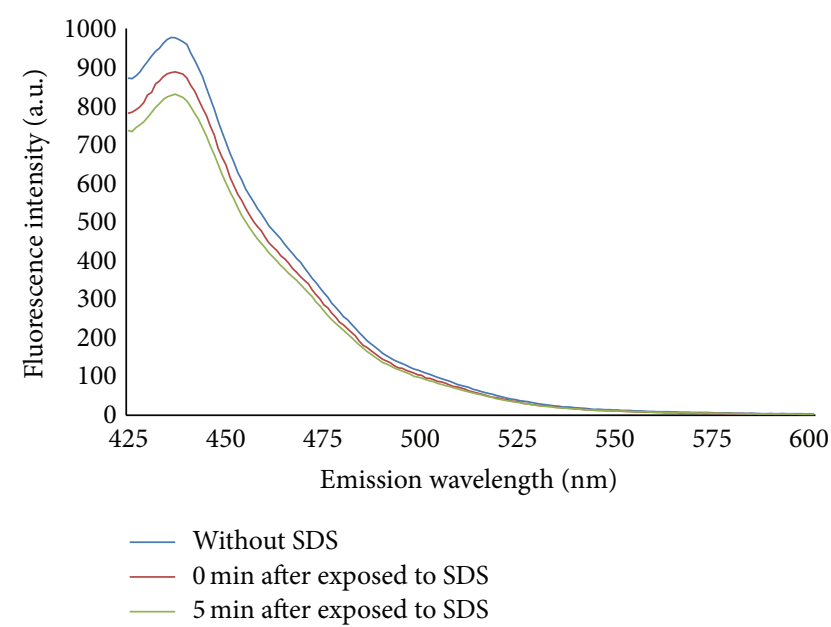

FIGURE 6: Fluorescence emission spectra of the bacteria E. coli GFP toxicity biosensor before and after the exposure to $10 \mathrm{ppm}$ SDS.

the fluorescence signals. Within $5 \mathrm{~min}$ after the exposure, more inhibitory reactions between the surfactant and GFP have taken place, which results in further reduction in the fluorescence intensity, to 830.35.

Many derivatives of GFPs have been used in the fabrication of whole-cell biosensors for environmental pollution monitoring purposes [32-36]. In bacteria E. coli GFP, the active site that was used in toxic detection and binding is the cysteine groups that were introduced into the beta barrel structure. The redox state of the cysteine determines the fluorescent properties of E. coli GFP toxicity biosensor. There are three modes of action that took place which contribute to the observed response: (i) redox reaction of thiol group of the GFP; (ii) denaturation of GFP protein which leads to loss of protein function; and (iii) disturbance of cell capsule's surface protein which leads to cell death $[26,37,38]$.

Binding of SDS to the thiol group of the GFP enhances redox reaction that gave effect on the fluorescence signals. The oxidation state of cysteine plays an important role in protein structure and formation. In its thiol form, cysteine is the most reactive amino acid and is often used for adding fluorescent groups. In oxidized forms, cysteine forms disulfide bonds, which are the primary covalent cross-links found in proteins that stabilize the native conformation of a protein. Cysteine is uniquely suited to sensing a range of redox signals as the thiol side-chain $(-\mathrm{SH})$ can be oxidized to several different reversible redox states such as disulphide $\left(\mathrm{R}-\mathrm{S}-\mathrm{S}-\mathrm{R}^{\prime}\right)$; sulphenic acid (R-SOH); and S-nitrosothiol (RSNO) [39].

SDS is known to cause denaturation of protein by binding to folded protein; its charged counterion will disturb the balance of the intrinsic charges of the protein and eventually unfold the protein with its negative charge [37]. Dilution of protein takes place when GFP consisting of 4-hydroxybenzylidene imidazolinone, which is commonly known as Y66 chromophore, is exposed to SDS. Y66 chromophore is responsible for the fluorescence emission of the 


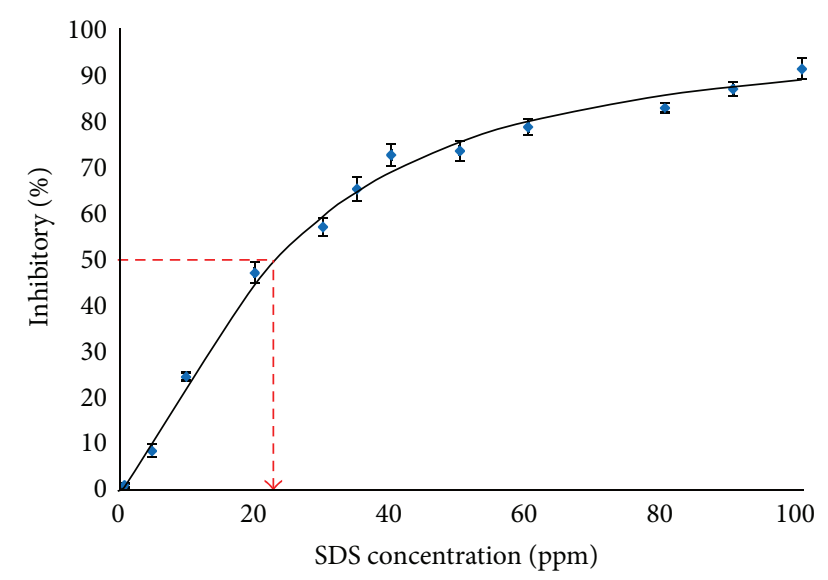

FIgURE 7: Dose-response curve of E. coli GFP toxicity biosensor towards SDS exposure. Red arrow with dotted line indicates the position of IC50 value of SDS $(n=3)$.

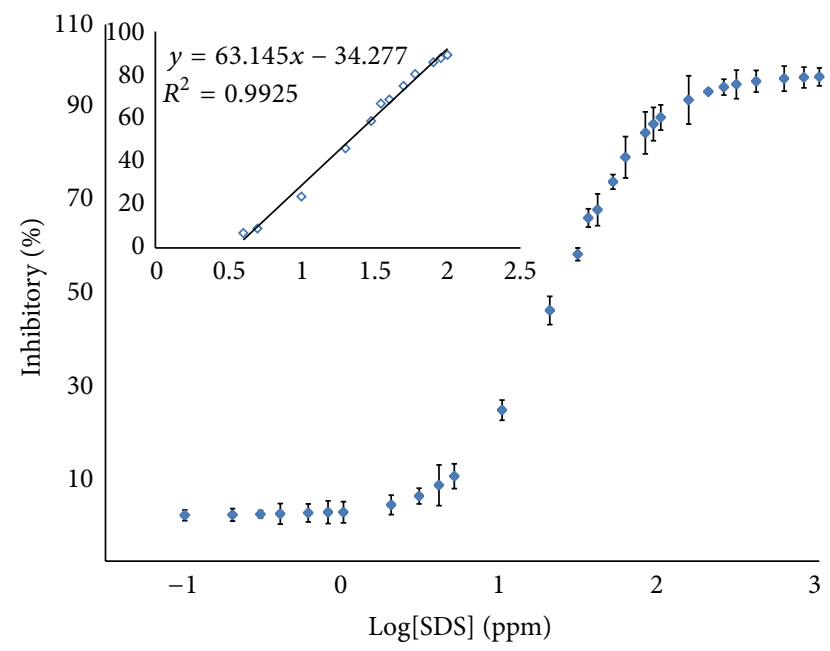

FIgURE 8: The calibration curve of $E$. coli GFP toxicity biosensor towards SDS exposure. Exposure time was set at $5 \mathrm{~min}, n=5$. Insert shows the dynamic linear range.

E. coli GFP toxicity biosensor [40]. Changing of protein confirmation inhibits the emission of the fluorescence.

Besides the unfolding of GFP, SDS is also believed to bind with proteins embedded on the phospholipid bilayer of the $E$. coli GFP cell capsule. During the exposure of SDS to the $E$. coli GFP toxicity biosensor, the surfactant decreases surface tension of the phospholipid bilayer. Binding of SDS changes the confirmation of embedded capsule proteins, which leads to the breakdown of phospholipid bilayer. Dispersion of phospholipid bilayers in cell membrane by SDS is also possible. Cell membranes play role in holding the bacteria contents (nucleus, proteins, cytoplasm, etc.) together. When the SDS works in decreasing the surface tension of the membrane, the cell membrane will deteriorate and dissemble [38]. E. coli GFP bacterial cells decompose when the cell membranes were gone, and hence no more fluorescence signal is being produced.
TABLE 2: Recovery data of $E$. coli GFP toxicity biosensor for the detection of SDS in tap water, $n=5$.

\begin{tabular}{lcc}
\hline $\begin{array}{l}\text { Real SDS } \\
\text { concentration }(\mathrm{ppm})\end{array}$ & $\begin{array}{c}\text { Detected SDS } \\
\text { concentration }(\mathrm{ppm})\end{array}$ & $\begin{array}{c}\text { Percentage of } \\
\text { recovery }(\%)\end{array}$ \\
\hline 10 & $9.58 \pm 0.08$ & 95.83 \\
20 & $20.70 \pm 0.28$ & 103.52 \\
50 & $55.81 \pm 0.90$ & 111.63 \\
80 & $81.23 \pm 1.01$ & 101.54 \\
100 & $91.36 \pm 1.24$ & 91.36 \\
\hline
\end{tabular}

TABle 3: Recovery data of E. coli GFP toxicity biosensor for the detection of SDS in Langat River water, $n=5$.

\begin{tabular}{lcc}
\hline $\begin{array}{l}\text { Real SDS } \\
\text { concentration }(\mathrm{ppm})\end{array}$ & $\begin{array}{c}\text { Detected SDS } \\
\text { concentration }(\mathrm{ppm})\end{array}$ & $\begin{array}{c}\text { Percentage of } \\
\text { recovery }(\%)\end{array}$ \\
\hline 10 & $9.30 \pm 0.22$ & 93.02 \\
20 & $20.24 \pm 0.33$ & 101.19 \\
50 & $53.62 \pm 0.91$ & 107.25 \\
80 & $80.62 \pm 0.89$ & 100.77 \\
100 & $91.42 \pm 0.60$ & 91.42 \\
\hline
\end{tabular}

TABLE 4: Recovery data of E. coli GFP toxicity biosensor for the detection of SDS in filtered drinking water, $n=5$.

\begin{tabular}{lcc}
\hline $\begin{array}{l}\text { Real SDS } \\
\text { concentration }(\mathrm{ppm})\end{array}$ & $\begin{array}{c}\text { Detected SDS } \\
\text { concentration }(\mathrm{ppm})\end{array}$ & $\begin{array}{c}\text { Percentage of } \\
\text { recovery }(\%)\end{array}$ \\
\hline 10 & $9.48 \pm 0.33$ & 94.76 \\
20 & $20.61 \pm 0.47$ & 103.07 \\
50 & $55.50 \pm 0.94$ & 111.01 \\
80 & $80.06 \pm 0.69$ & 100.07 \\
100 & $91.25 \pm 1.11$ & 91.25 \\
\hline
\end{tabular}

3.4. Median Inhibitory Concentration of SDS. The response of E. coli GFP toxicity biosensor towards SDS exposure shows a sigmoid dose-response curve (Figure 7). Percentage of SDS toxicity inhibition increases when the concentration of SDS increases. The decrease in fluorescence signal of $E$. coli GFP toxicity biosensor after SDS exposure is an effect of cytotoxicity. IC50 of SDS towards E. coli GFP toxicity biosensor is determined as $22.75 \mathrm{ppm}$. This indicates that half of the total responsive activity of the toxicity biosensor will be induced when it is exposed to that dosage of SDS. SDS induces activity of E. coli GFP toxicity biosensor at an exponential rate at lower concentrations, while the response is close to plateau at higher levels due to maximum toxicity effect.

3.5. E. coli GFP Toxicity Biosensor towards SDS Detection. E. coli GFP toxicity biosensor has been applied to detect SDS in a wide range of 0.1-1000 ppm. The SDS inhibition response has been studied (Figure 8). Inhibitory effect of SDS towards E. coli GFP toxicity biosensor can be observed clearly from concentration of $2.0 \mathrm{ppm}$ and onwards. The sigmoidal calibration curve indicates that E. coli GFP toxicity biosensor has a wide detection range, with dynamic linear range falling 
TABle 5: Comparison between E. coli GFP toxicity biosensor and reported SDS immobilized whole-cell bacteria biosensors.

\begin{tabular}{lcccc}
\hline Parameter & This study & {$[22]$} & {$[23]$} & [27] \\
\hline Bacteria & E. coli GFP & Pseudomonas rathonis & Pseudomonas sp. & Comamonas testosteroni TI \\
Immobilization matrix & $k$-Carrageenan & Gel agar & Gel agar & $0.04-0.90$ \\
Dynamic linear range (ppm) & $4.0-100$ & $1.0-200$ & $2.48 \times 10^{-4}$ & - \\
Lowest detection limit (ppm) & 1.7 & $\sim 0.25-0.75$ & $0.16 \pm 0.02$ & $0.25-0.5$ \\
IC50 (ppm) & 22.75 & - & $1.7-2.5$ & - \\
Response time (min) & $<1.0$ & $1.7-2.5$ & - & $12-15$ \\
Reproducibility (\%) & 0.76 & 3.13 & - & - \\
Repeatability (\%) & 0.72 & - & $3-5$ & 10 \\
Biosensor stability (days) & 46 & $2-3$ & & - \\
\hline
\end{tabular}

at $4-100 \mathrm{ppm}$. SDS with concentrations of $300-1000 \mathrm{ppm}$ induces high level of inhibition which leads to a plateau at $\sim 100 \%$. SDS with concentration falling in that range gives high toxicity effect to $E$. coli GFP cells resulting in massive cell death, which gives rise to a quick drop in the fluorescence signal. LOD of E. coli GFP toxicity biosensor for SDS detection has been determined to be $1.7 \mathrm{ppm}$. SDS at lower concentration might take longer ( $>5 \mathrm{~min}$ ) to cause toxicity, or the toxicity level is too low and the damage is resistible by E. coli GFP cells.

3.6. Recovery Performance of E. coli GFP Toxicity Biosensor. E. coli GFP toxicity biosensor was exposed to a series of SDS (concentration: 10-100 ppm) prepared in three different real water sample backgrounds. Recovery data for the biosensor performance in each water background were shown in Tables 2-4. E. coli GFP toxicity biosensor showed a recovery percentage of $91.36-111.63 \%$ when working under tap water background (Table 2). For E. coli, GFP toxicity biosensor which worked under the real river water background gave a recovery level of $91.42-107.25 \%$ (Table 3), while, for water background of drinking water, E. coli GFP toxicity biosensor is able to detect SDS for a recovery percentage of 91.25$111.01 \%$ (Table 4 ). The biosensor response slightly varies from a controlled experiment conducted in deionized water background (data not shown) due to interaction of SDS and $E$. coli GFP with free nontarget radicles present in the real water samples. Nevertheless, high level of recovery performance enables E. coli GFP toxicity biosensor to be applied in real environment.

Optimized E. coli GFP toxicity biosensor performance is compared with reported immobilized whole-cell bacteria biosensors that were fabricated to apply in SDS detection (Table 5). In our knowledge, there was no SDS-detection bacterial biosensor fabricated using $k$-Carrageenan as a matrix for cell immobilization being reported. Our toxicity biosensor has a comparatively wide dynamic linear range. Although the LOD of E. coli GFP toxicity biosensor is not as low as others, it has an IC50 value which is higher as compared to the one reported by Taranova et al. [23]. E. coli GFP toxicity biosensor is able to respond to SDS detection in seconds, while the reported biosensors would need minutes. The fabricated E. coli GFP toxicity biosensor possesses high reproducibility and repeatability as compared to the rest.
Furthermore, our biosensor is stable for a longer time among comparison.

\section{Conclusions}

A sensitive and optimized E. coli GFP toxicity biosensor has been fabricated, with minimum response time as short as 5-10 s. Sodium dodecyl sulfate shows an inhibition reaction on the fluorescent ability of the bacteria, which was due to alteration of GFP protein and capsule surface embedded functional protein upon SDS binding and lipid dispersion criteria of SDS surfactant towards the phospholipid bilayer bacterial cell membrane. E. coli GFP toxicity biosensor is able to work in real water backgrounds to detect toxicity induced by SDS in tap water, river water, and drinking water. This study gives an alternative for SDS toxicity detection in water resources, which is comparatively economic, portable, and easy to prepare.

\section{Conflict of Interests}

The authors declare that there is no conflict of interests regarding the publication of this paper.

\section{Acknowledgment}

This work is funded by the National University of Malaysia (UKM) via Research Grants DPP-2014-060 and NND/ND/2/ TD11-009.

\section{References}

[1] O. Shimomura, "The discovery of aequorin and green fluorescent protein," Journal of Microscopy, vol. 217, no. 1, pp. 3-15, 2005.

[2] D. C. Prasher, V. K. Eckenrode, W. W. Ward, F. G. Prendergast, and M. J. Cormier, "Primary structure of the Aequorea victoria green-fluorescent protein," Gene, vol. 111, no. 2, pp. 229-233, 1992.

[3] J. Lippincott-Schwartz and G. H. Patterson, "Development and use of fluorescent protein markers in living cells," Science, vol. 300, no. 5616, pp. 87-91, 2003.

[4] R. Heim, D. C. Prasher, and R. Y. Tsien, "Wavelength mutations and posttranslational autoxidation of green fluorescent protein," 
Proceedings of the National Academy of Sciences of the United States of America, vol. 91, no. 26, pp. 12501-12504, 1994.

[5] M. Stuart, D. Lapworth, E. Crane, and A. Hart, "Review of risk from potential emerging contaminants in UK groundwater," Science of the Total Environment, vol. 416, pp. 1-21, 2012.

[6] V. Chaturvedi and A. Kumar, "Toxicity of sodium dodecyl sulfate in fishes and animals. A review," International Journal of Applied Biology and Pharmaceutical Technology, vol. 1, no. 2, pp. 630-633, 2008.

[7] J. R. Marchesi, S. A. Owen, G. F. White, W. A. House, and N. J. Russell, "SDS-degrading bacteria attach to riverine sediment in response to the surfactant or its primary biodegradation product dodecan-1-ol," Microbiology, vol. 140, no. 11, part 1, pp. 2999-3006, 1994.

[8] C. G. van Ginkel, "Complete degradation of xenobiotic surfactants by consortia of aerobic microorganisms," Biodegradation, vol. 7, no. 2, pp. 151-164, 1996.

[9] J. Piret, A. Désormeaux, and M. G. Bergeron, "Sodium lauryl sulfate, a microbicide effective against enveloped and nonenveloped viruses," Current Drug Targets, vol. 3, no. 1, pp. 17-30, 2002.

[10] E. Barbieri, P. V. Ngan, and V. Gomes, "The effect of SDS, sodium dodecyl sulfate, on the metabolism and swimming capacity of Cyprinus carpio," Revista Brasileira de Biologia, vol. 58, no. 2, pp. 263-271, 1998.

[11] A. J. S. Rocha, V. Gomes, P. V. Ngan, M. J. A. C. R. Passos, and R. R. Furia, "Effects of anionic surfactant and salinity on the bioenergetics of juveniles of Centropomus parallelus (Poey)," Ecotoxicology and Environmental Safety, vol. 68, no. 3, pp. 397404, 2007.

[12] M. Rosety, F. J. Ordoñez, M. Rosety-Rodríguez et al., "Comparative study of the acute toxicity of anionic surfactans alkyl benzene sulphonate (ABS) and sodium dodecyl sulphate (SDS) on gilthead, Sparus aurata L., eggs," Histology and Histopathology, vol. 16, no. 4, pp. 1091-1095, 2001.

[13] N. J. Fendinger, D. J. Versteeg, E. Weeg, S. Dyer, and R. A. R. Rapaport, "Environmental behavior and fate of anionic surfactants partners," in Environmental Chemistry of Lakes and Reservoirs, pp. 527-557, American Chemical Society, Washington, DC, USA, 1994.

[14] M. Lindberg, B. Forslind, S. Sagstrom, and G. M. Roomans, "Elemental changes in guinea pig epidermis at repeated exposure to sodium lauryl sulfate," Acta Dermato-Venereologica, vol. 72, no. 6, pp. 428-431, 1992.

[15] Y. Miura, H. Hisaki, B. Fukushima, T. Nagai, and T. Ikeda, "Detergent induced changes in serum lipid composition in rats," Lipids, vol. 24, no. 11, pp. 915-918, 1989.

[16] J. J. M. van de Sandt, T. A. Bos, and A. A. J. J. L. Rutten, "Epidermal cell proliferation and terminal differentiation in skin organ culture after topical exposure to sodium dodecyl sulphate," In Vitro Cellular and Developmental Biology-Animal, vol. 31, no. 10, pp. 761-766, 1995.

[17] E. Olkowska, Ż. Polkowska, and J. Namieśnik, "Analytics of surfactants in the environment: problems and challenges," Chemical Reviews, vol. 111, no. 9, pp. 5667-5700, 2011.

[18] R. Alzaga, A. Peña, L. Ortiz, and J. M. Bayona, "Determination of linear alkylbenzensulfonates in aqueous matrices by ionpair solid-phase microextraction-in-port derivatization-gas chromatography-mass spectrometry," Journal of Chromatography A, vol. 999, no. 1-2, pp. 51-60, 2003.

[19] J. Riu, P. Eichhorn, J. A. Guerrero, T. P. Knepper, and D. Barceló, "Determination of linear alkylbenzenesulfonates in wastewater treatment plants and coastal waters by automated solid-phase extraction followed by capillary electrophoresisUV detection and confirmation by capillary electrophoresismass spectrometry," Journal of Chromatography A, vol. 889, no. 1-2, pp. 221-229, 2000.

[20] Y. An, H. Bai, C. Li, and G. Shi, "Disassembly-driven colorimetric and fluorescent sensor for anionic surfactants in water based on a conjugated polyelectrolyte/dye complex," Soft Matter, vol. 7, no. 15, pp. 6873-6877, 2011.

[21] J. Fan and C. Yin, "Methylene green SDS detection assay," Tech. Rep., Bowdish Lab, McMaster University, Hamilton, Canada, 2012.

[22] A. N. Reshetilov, I. N. Semenchuk, P. V. Iliasov, and L. A. Taranova, "The amperometric biosensor for detection of sodium dodecyl sulfate," Analytica Chimica Acta, vol. 347, no. 1-2, pp. 19-26, 1997.

[23] L. Taranova, I. Semenchuk, T. Manolov, P. Iliasov, and A. Reshetilov, "Bacteria-degraders as the base of an amperometric biosensor for detection of anionic surfactants," Biosensors and Bioelectronics, vol. 17, no. 8, pp. 635-640, 2002.

[24] I. E. Tsybulskii and M. A. Sazykina, "New biosensors for assessment of environmental toxicity based on marine luminescent bacteria," Applied Biochemistry and Microbiology, vol. 46, no. 5, pp. 505-510, 2010.

[25] D. Futra, S. Surif, A. Ahmad et al., "Determination of $\mathrm{Cu}$ (II) toxicity using a biosensor with immobilized recombinant Escherichia coli roGFP cells," in Environmental Risk Assessment and Management in Japan and Malaysia, Graduate School of Engineering, Kyoto University and Institute for Environmental and Development (LESTARI), 2009.

[26] C. R. Arias-Barreiro, K. Okazaki, A. Koutsaftis et al., "A bacterial biosensor for oxidative stress using the constitutively expressed redox-sensitive protein roGFP2," Sensors, vol. 10, no. 7, pp. 6290-6306, 2010.

[27] L. A. Taranova, A. P. Fesaǐ, G. V. Ivashchenko, A. N. Reshetilov, M. Winter-Nielsen, and J. Emneus, "Comamonas testosteroni strain TI as a potential base for a microbial sensor detecting surfactants," Prikladnaia Biokhimiia i Mikrobiologiia, vol. 40, no. 4, pp. 472-477, 2004.

[28] D. McHugh, Production and Utilization of Products from Commercial Seaweeds, Food and Agriculture Organization of United Nations, Rome, Italy, 1987.

[29] E. R. Morris, D. A. Rees, and G. Robinson, "Cation-specific aggregation of carrageenan helices: domain model of polymer gel structure," Journal of Molecular Biology, vol. 138, no. 2, pp. 349-362, 1980

[30] C. Rochas and S. Landry, "Molecular organization of kappa carrageenan in aqueous solution," Carbohydrate Polymers, vol. 7, no. 6, pp. 435-447, 1987.

[31] S. K. H. Gulrez, S. Al-Assaf, and G. O. Philips, "Hydrogels: methods of preparation, characterisation and applications," in Progress in Molecular and Environmental Bioengineering: From Analysis and Modeling to Technology Applications, A. Carpi, Ed., InTech, 2011.

[32] H. J. Cha, R. Srivastava, V. N. Vakharia, G. Rao, and W. E. Bentley, "Green fluorescent protein as a noninvasive stress probe in resting Escherichia coli cells," Applied and Environmental Microbiology, vol. 65, no. 2, pp. 409-414, 1999.

[33] D. C. Joyner and S. E. Lindow, "Heterogeneity of iron bioavailability on plants assessed with a whole-cell GFP-based bacterial biosensor," Microbiology, vol. 146, no. 10, pp. 2435-2445, 2000. 
[34] M. T. Brandl, B. Quiñones, and S. E. Lindow, "Heterogeneous transcription of an indoleacetic acid biosynthetic gene in Erwinia herbicola on plant surfaces," Proceedings of the National Academy of Sciences of the United States of America, vol. 98, no. 6, pp. 3454-3459, 2001.

[35] J. H. J. Leveau and S. E. Lindow, "Appetite of an epiphyte: quantitative monitoring of bacterial sugar consumption in the phyllosphere," Proceedings of the National Academy of Sciences of the United States of America, vol. 98, no. 6, pp. 3446-3453, 2001.

[36] W. G. Miller, M. T. Brandl, B. Quiñones, and S. E. Lindow, "Biological sensor for sucrose availability: relative sensitivities of various reporter genes," Applied and Environmental Microbiology, vol. 67, no. 3, pp. 1308-1317, 2001.

[37] T. Cserháti, E. Forgács, and G. Oros, "Biological activity and environmental impact of anionic surfactants," Environment International, vol. 28, no. 5, pp. 337-348, 2002.

[38] D. R. Caprette, Preparing Protein Samples for Electrophoresis, 2014, http://www.ruf.rice.edu/ bioslabs/studies/sds-page/ denature.html.

[39] M. Conte and K. Carroll, "The chemistry of thiol oxidation and detection," in Oxidative Stress and Redox Regulation, U. Jakob and D. Reichmann, Eds., pp. 1-42, Springer, Amsterdam, The Netherlands, 2013.

[40] H. Niwa, S. Inouye, T. Hirano et al., "Chemical nature of the light emitter of the Aequorea green fluorescent protein," Proceedings of the National Academy of Sciences of the United States of America, vol. 93, no. 24, pp. 13617-13622, 1996. 

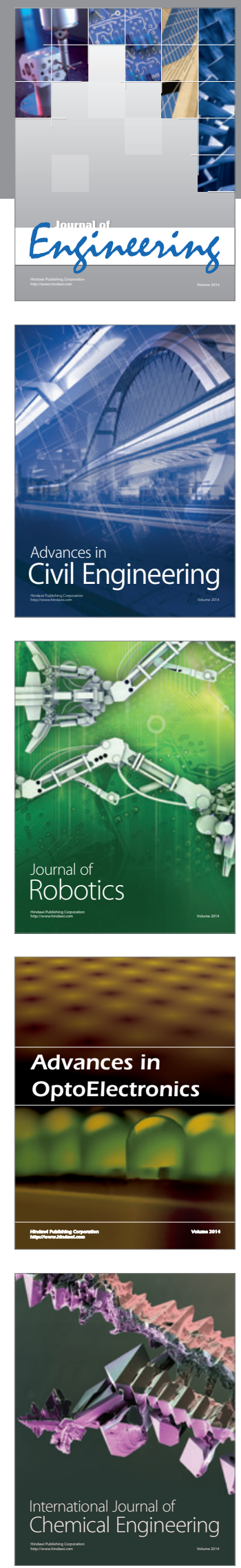

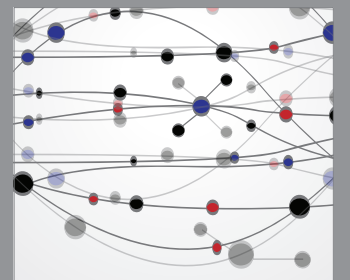

The Scientific World Journal
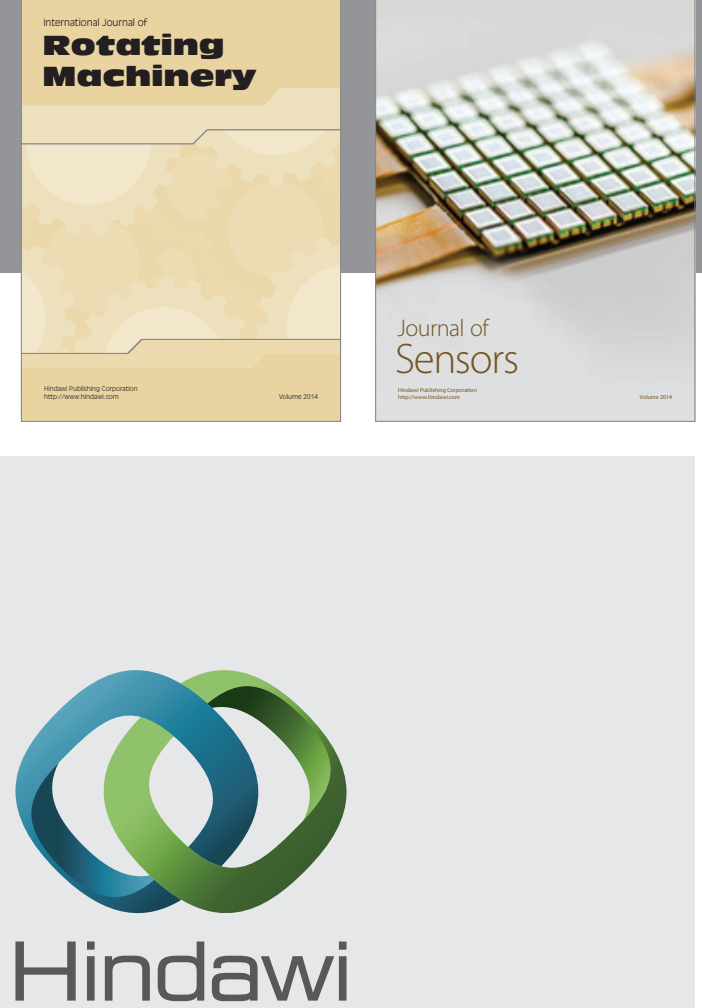

Submit your manuscripts at http://www.hindawi.com
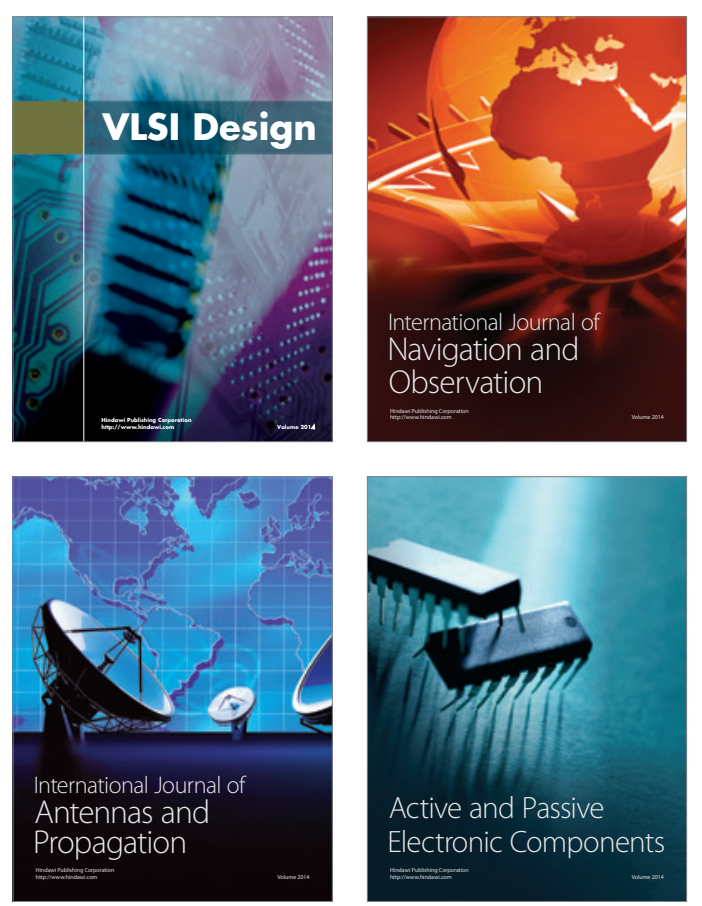
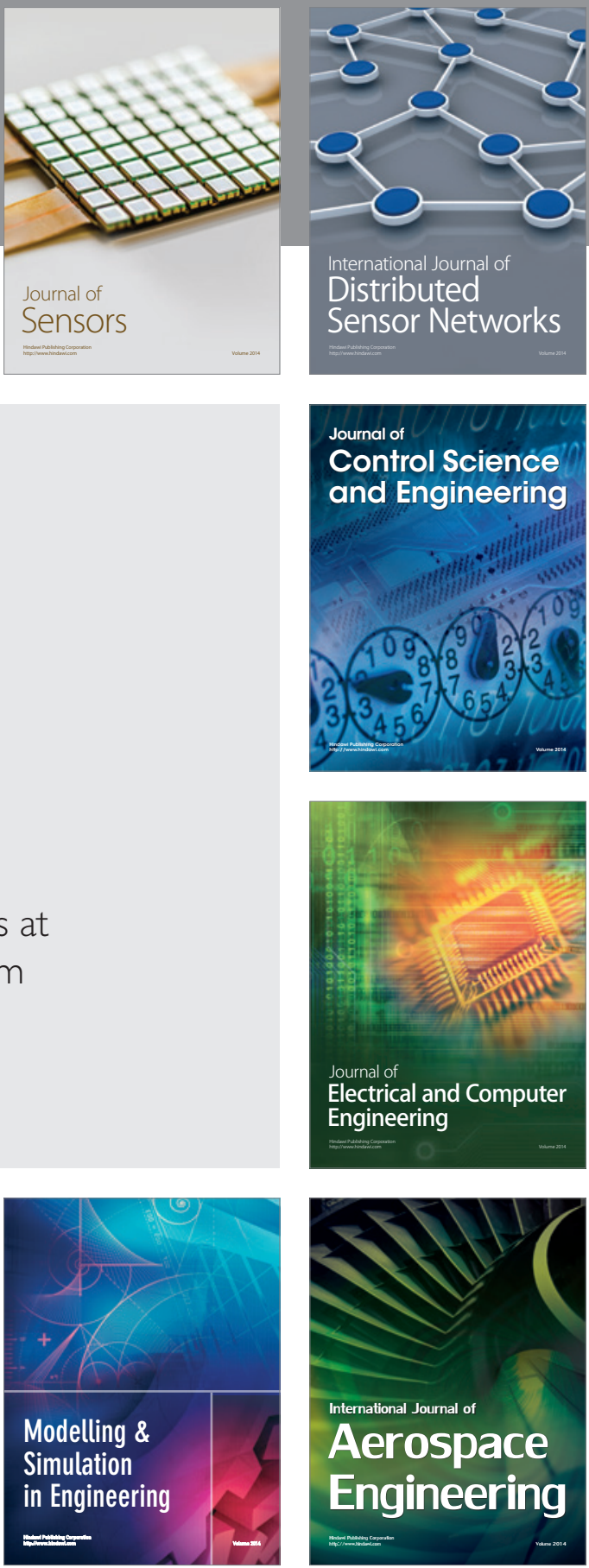

Journal of

Control Science

and Engineering
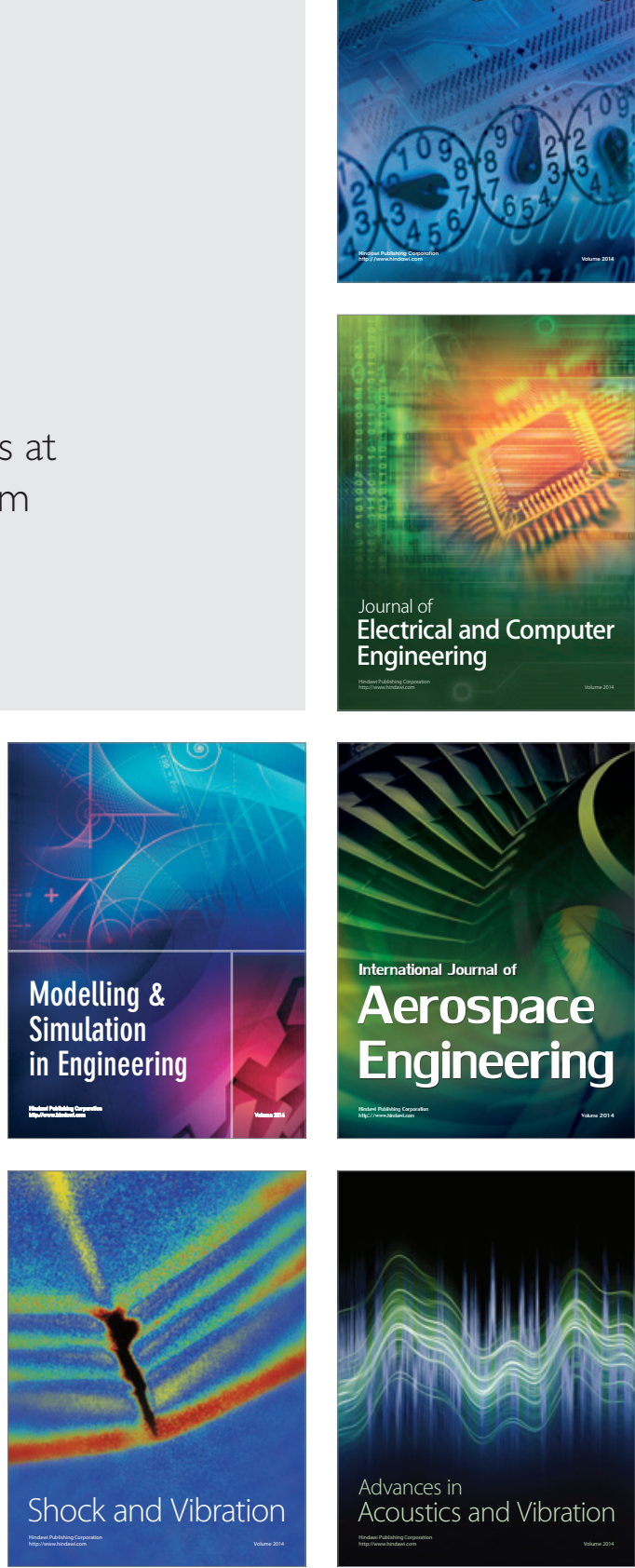